\title{
Duodenal GLP-1 signaling regulates hepatic glucose production through a PKC- $\delta$-dependent neurocircuitry
}

\author{
Mengliu Yang ${ }^{1,6}$, Jinzhi Wang ${ }^{2,6}$, Shaobo $\mathrm{Wu}^{3,6}$, Lei Yuan ${ }^{1}$, Xiaodong Zhao ${ }^{2}$, Chaohong Liu², Jing Xie ${ }^{1}$, Yanjun Jia ${ }^{2}$, Yerui Lai ${ }^{1}$, \\ Allan Zijian Zhao ${ }^{4}$, Guenther Boden ${ }^{5}$, Ling Liं ${ }^{\star, 1}$ and Gangyi Yang ${ }^{\star, 1}$
}

Intestinal glucagon-like peptide-1 (GLP-1) is a hormone that stimulates insulin secretion and acts as a neuropeptide to control glucose homeostasis, but little is known whether intestinal GLP-1 has any effect in the control of hepatic glucose production (HGP). Here we found that intraduodenal infusion of GLP-1 activated duodenal PKC- $\delta$, lowered HGP and was accompanied by a decrease in hepatic expression of gluconeogenic enzymes and an increase in hepatic insulin signaling in rats. However, gut co-infusion of either the GLP-1 receptor antagonist Ex-9, or the PKC- $\delta$ inhibitor rottlerin with GLP-1, negated the ability of gut GLP-1 to lower HGP and to increase hepatic insulin signaling during clamps. The metabolic and molecular signal effects of duodenal GLP-1 were also negated by co-infusion with tetracaine, pharmacologic inhibition of $N$-methyl-D-aspartate receptors within the dorsalvagal complex, or hepatic vagotomy in rats. In summary, we identified a neural glucoregulatory function of gut GLP-1 signaling.

Cell Death and Disease (2017) 8, e2609; doi:10.1038/cddis.2017.28; published online 9 February 2017

It is well established that nutrients can stimulate the release of gut-peptide hormones, such as cholecystokinin (CCK), pancreatic polypeptide, peptide $Y Y$ and glucagon-like peptide-1 (GLP-1), which are involved in the regulation of food intake and gastrointestinal function. ${ }^{1-3}$ GLP-1 is a 30 amino acid peptide produced by post-translational processing of the proglucagon gene product in enteroendocrine cells (L-cells), which are most prevalent in the mucosa of the distal small intestine and colon. ${ }^{4}$ However, endocrine cells that produce GLP-1 also can be found throughout all regions of the porcine, rat and human small intestine. ${ }^{5}$ The actions of GLP-1 are mediated by specific GLP-1 receptors (GLP-1R), a G-proteincoupled receptor (GPR). In rodents and humans, a single structurally identical GLP-1R has been identified and is expressed in a wide range of tissues, including $\alpha-, \beta$ - and $\delta$-cells of the pancreatic islets, lung, heart, kidney, stomach, intestine, pituitary, skin, nodose ganglion neurons of the vagus nerve, and several regions of the central nervous system (CNS) including the hypothalamus and brainstem. ${ }^{5}$ Central or peripheral GLP-1R activation has been shown to cause a variety of effects, including an increase in insulin release, a reduction of food intake ${ }^{2,6}$ and an increase in insulin sensitivity in both rodents and humans. ${ }^{7-9}$ In addition, GLP-1 inhibits gastric emptying, ${ }^{10}$ decreases body weight ${ }^{11}$ and exerts a $\beta$-cell protective effects and beneficial cardiovascular actions. ${ }^{5,12}$ Furthermore, it has also been demonstrated that the GLP-1R is expressed by intestinal mucosal cells, paneth cells and enteric neurons, that activation of receptor expression in mucosal cells is specific to GLP-1 and is regulated by neuronal inputs. ${ }^{13}$ Therefore, it is possible that once secreted in a paracrine fashion (local to the site of release in the small intestine), GLP-1 activates GLP-1Rs expressed in mucosal cells of the upper gastrointestinal tract through vagal afferent neurons to regulate glucose production. ${ }^{14}$ However, whether intestinal GLP-1 has any effect in the control of hepatic glucose production (HGP) has not been addressed.

As the majority of intestinally derived GLP-1 is rapidly degraded by the dipeptidyl peptidase-4 (DPP-4) enzyme and similar endopeptidases, the circulating GLP-1 levels are low. ${ }^{15}$ Currently, long-lasting active analogs or agonist of GLP-1 have already been developed as drugs. ${ }^{11}$ In the present study, we described a novel role of intestinal GLP-1 that triggers a gut-brain-liver neuronal network to regulate HGP by using liraglutide, a human GLP-1R agonist, and Exenatide, a natural analog of GLP-1.

\section{Results}

Duodenal GLP-1 lowers glucose production. To examine whether GLP-1R is expressed in the duodenum, GLP-1Rimmunoreactivity was performed in rat duodenum tissue. GLP-1R immunoreactive cells were seen in Brunner's gland epithelium, with a predominant basolateral membraneassociated staining of epithelial cells (Supplementary Figure S1). To investigate whether intestinal GLP-1 activation

\footnotetext{
${ }^{1}$ Department of Endocrinology, The Second Affiliated Hospital, Chongqing Medical University, Chongqing, China; ${ }^{2}$ Chongqing Key Lab of Child Infection and Immunity Children's Hospital of Chongqing Medical University, Chongqing, China; ${ }^{3}$ The Key Laboratory of Laboratory Medical Diagnostics in the Ministry of Education and Department of Clinical Biochemistry, College of Laboratory Medicine, Chongqing Medical University, Chongqing, China; ${ }^{4}$ Institute of Biomedical and Pharmaceutical Sciences, Guangdong University of Technology, Guangzhou, Guangdong, China and ${ }^{5}$ The Division of Endocrinology/Diabetes/Metabolism and the Clinical Research Center, Temple University School of Medicine, Philadelphia, PA, USA

*Corresponding author: G Yang or L Li, Department of Endocrinology, the Second Affiliated Hospital, Chongqing Medical University, Chongqing 400010, China. Tel: +86 23 68485216; Fax: +86 23 68485005; E-mail: gangyiyang@163.com or lingli31@ hotmail.com

${ }^{6}$ These authors contributed equally to this work.

Received 19.8.16; revised 13.12.16; accepted 13.12.16; Edited by A Stephanou
} 
regulates glucose production (Figure 1a), we selectively activated duodenal GLP-1 signaling via direct intraduodenal liraglutide or Exenatide administration in vivo. First, intraduodenal liraglutide or Exenatide was infused $(0,10,30$ or $60 \mathrm{pmol} / \mathrm{kg} / \mathrm{min}$ ) and demonstrated a dose-dependent increase of GIR during clamps. As shown in Supplementary

a

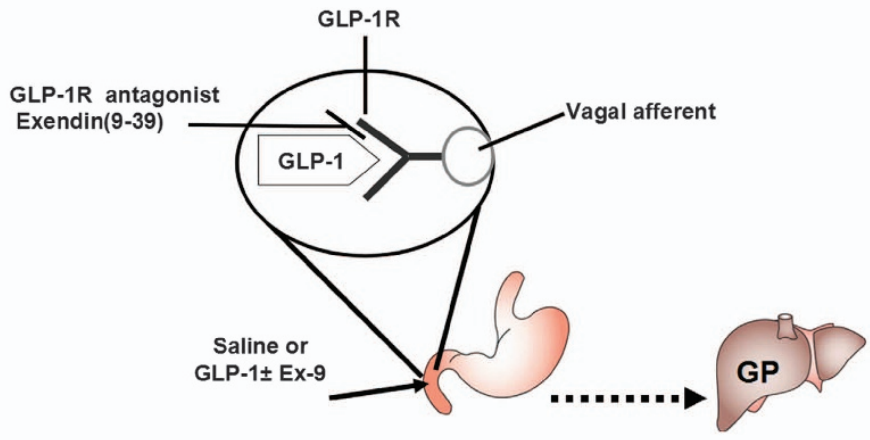

b

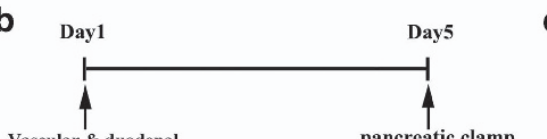

catheters

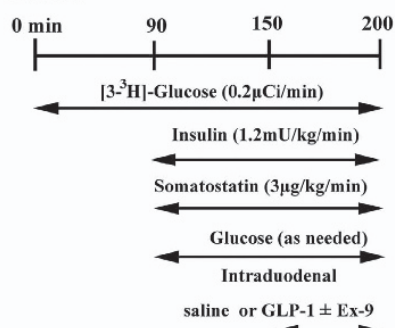

d

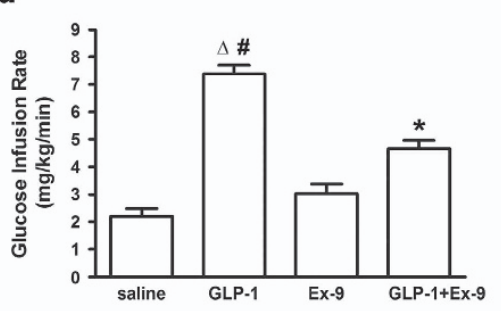

f

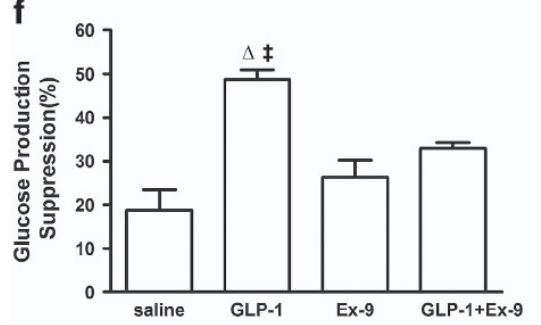

C
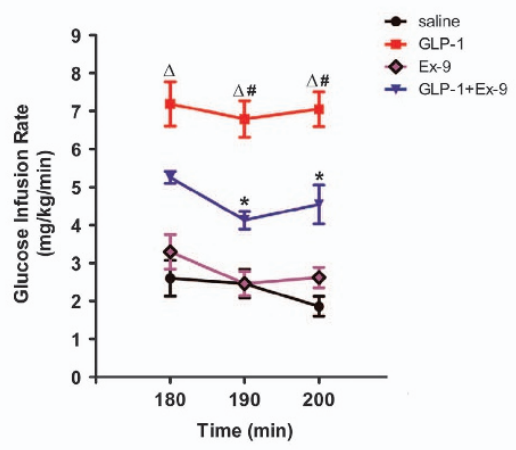

e

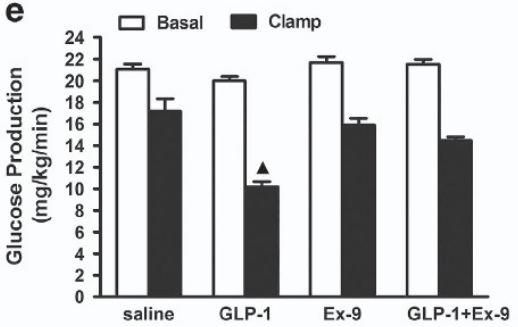

g

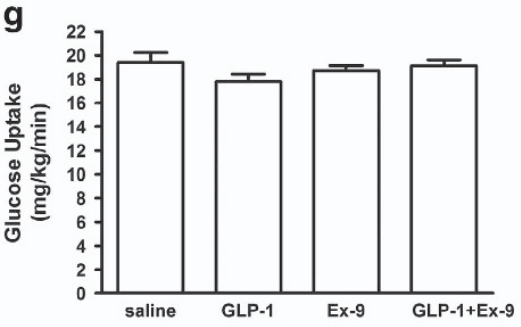

h

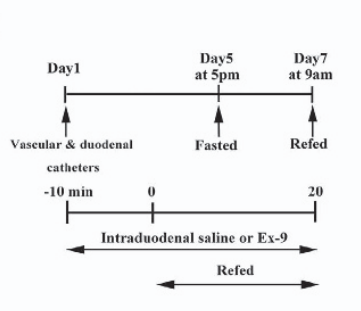

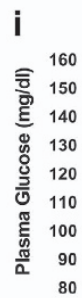
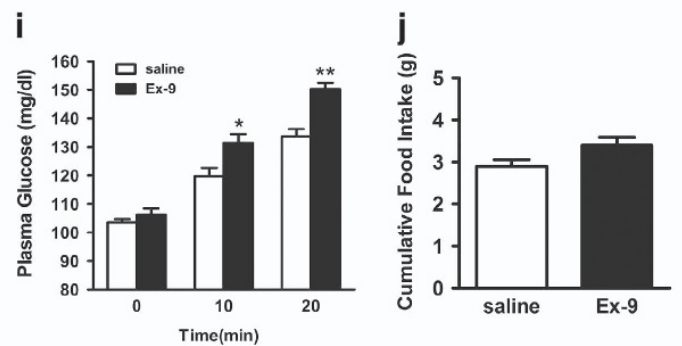
Figure S2, $30 \mathrm{pmol} / \mathrm{kg} / \mathrm{min}$ infusion of liraglutide or Exenatide increased GIR by approximately 3.4- and 3.7-fold $(7.4 \pm 0.3$ for liraglutide and $8.2 \pm 0.4 \mathrm{mg} / \mathrm{kg} / \mathrm{min}$ for Exenatide versus $2.2 \pm 0.3 \mathrm{mg} / \mathrm{kg} / \mathrm{min}$ for saline, all $P<0.01)$. Based on considerations for preventing increase of circulating GLP-1 levels, $30 \mathrm{pmol} / \mathrm{kg} / \mathrm{min}$ was selected for all further experiments. During the clamp, plasma glucose, insulin and free fatty acid (FFA) were maintained at basal levels (Supplementary Table S1). However, intraduodenal administration of GLP-1 increased the GIR required to maintain euglycemia, suggested an enhancement of insulin sensitivity (Figures 1c and d). This was due to an inhibition of HGP (Figure 1e) rather than changes in the rate of peripheral glucose uptake (Figure 1g). In addition, we found that the effects of Exenatide on GIR and HGP were similar to those of liraglutide (Supplementary Figure S3). Thus, Exenatide was selected for further experiments.

In another set of rats, we performed intraduodenal GLP-1 (30 pmol/ $\mathrm{kg} / \mathrm{min}$ ) administration for $60 \mathrm{~min}$ and found that plasma GLP-1 levels did not change at $60 \mathrm{~min}$ (Supplementary Table S2). GLP-1 levels in the portal vein were slightly increased but the difference did not reach statistically significance. Therefore, an increase of GLP-1 in the duodenum lowers glucose production without changes in circulating GLP-1 or insulin levels. These results suggest that the GLP-1 doses that were used had only local (mucosa) but no systemic effects.

Pharmacological inhibition of GLP-1 receptors disrupts the effects of duodenal GLP-1 on glucose production. To investigate whether duodenal GLP-1 infusion activates GLP-1 receptors and evaluate whether GLP-1 receptors in intestinal mucosal cells are required for the effect of gut GLP-1 on HGP, we co-infused the GLP-1 receptor inhibitor Ex-9 with GLP-1 into the duodenum (Figures 1a and b). This partially prevented GLP-1 to increase glucose infusion rates (GIRs) (Figures 1c and d) and to lower HGP (Figures 1e and $\mathrm{f}$ ), while glucose uptake was comparable in both groups (Figure 1g). The infusion of Ex-9 alone did not affect glucose kinetics (Figures $1 \mathrm{c}-\mathrm{g}$ ). These results show that GLP-1 receptors are required for GLP-1 action in the gut to lower HGP.

Duodenal GLP-1 lowers HGP through a gut-brain-liver axis. To examine whether gut GLP-1 lowers glucose production through a neuronal network, we co-infused the GLP-1 with the local anesthetic tetracaine, a blocker of the ryanodine receptors, into the duodenum. Intraduodenal tetracaine alone did not affect GIR and HGP (Figures $2 \mathrm{c}-\mathrm{g}$ ). However, when tetracaine was co-administered with GLP-1, the ability of gut GLP-1 to increase GIR (Figures 2c and $\mathrm{d}$ ) and lower glucose production was prevented (Figures $2 e$ and f). Glucose uptake was not affected by both duodenal GLP-1 and tetracaine (Figure 2g). Therefore, the data suggest that duodenal GLP-1 may lower HGP via activation of gut innervation of vagal afferent nerves.

Vagal afferent nerves terminate at the nucleus of the solitary tract (NTS) within the DVC. N-methyl-D-aspartate (NMDA) receptors in the duodenum originating neurons in the NTS of the hindbrain mediate gut signals initiated by hormone or nutrients to regulate food intake and glucose metabolism. We therefore inhibited the NMDA receptors-mediated neuronal transmission in the NTS by administration of MK-801, an NMDA receptor blocker (Figures $2 \mathrm{a}$ and $\mathrm{b}$ ). MK-801 infusion alone did not affect glucose kinetics (Figures 2c-g). When NTS MK-801was co-administered with duodenal GLP-1, it negated the ability of gut GLP-1 to increase GIR (Figures 2c and $d$ ) and lower HGP (Figures $2 e$ and $f$ ). This effect of NTS MK-801 occurred independent of changes in glucose uptake rate (Figure $2 \mathrm{~g}$ ) and insulin levels (Supplementary Table S1).

To investigate the descending pathway that mediates the effect of duodenal GLP-1 on glucose production, we next investigate whether surgical transection of the hepatic vagus nerve is sufficient to alter the effect of duodenal GLP-1 infusion on hepatic production in vivo (Figure 2a). We performed pancreatic-insulin clamp studies in conscious rats that underwent HVAG (Figure 2b). HAVG alone did not affect GIR and HGP. However, HAVG abolished the ability of gut GLP-1 to increase GIR (Figures 2c and d) and lower glucose production (Figures $2 e$ and f), while glucose uptake was unchanged (Figure 2g). Collectively, these results indicate that duodenal GLP-1 increases vagal afferent neuronal activity to switch a gut-brain-liver axis to regulate HGP.

Pharmacological inhibition of GLP-1 receptors disrupts glucose homeostasis during fasting-refeeding. Next, we investigated the effects pharmacological inhibition of gut GLP-1 receptors on glucose homeostasis during fastingrefeeding. When fasting rats are refed, the elevation of plasma glucose is restrained as a result of glucose production inhibition. ${ }^{16}$ We reasoned that if the nutrientrelated signals can activate GLP-1 receptors to regulate HGP, the inhibition of gut GLP-1 receptors should disturb the regulation of HGP during refeeding. Rats were fasted for $40 \mathrm{~h}$ after 5 days of vascular and duodenal surgeries (Figure $1 \mathrm{~h}$ ). Blood glucose rose at 10 and $20 \mathrm{~min}$ of refeeding for the

Figure 1 Gut GLP-1 inhibits liver glucose production through GLP-1 receptors. (a) Schematic representation of working hypothesis. GLP-1 with or without Ex-9 was infused through a duodenal catheter. GLP-1R, GLP-1 receptor; GP, glucose production. (b) Experimental procedure and clamp protocol. Duodenal catheter or venous and arterial catheters were implanted on day 1. The pancreatic (basal insulin) clamp studies were performed on day 5. (c) Glucose infusion rates (GIR) during the steady state of clamp (180$200 \mathrm{~min}$ ). (d) Cumulative GIR during the steady state of clamp. (e) Hepatic glucose production (HGP). (f) Suppression of HGP during the clamp period expressed as the percentage reduction from basal HGP. (g) Glucose uptake. Data are means \pm S.E.M. (saline $(n=8), \mathrm{GLP}-1(n=7)$, Ex-9 $(n=6), \mathrm{GLP}-1+\mathrm{Ex}-9(n=8))$. ${ }^{\star} P<0.05,{ }^{\Delta} P<0.01$ versus saline and Ex-9; ${ }^{\ddagger} P<0.05,{ }^{\#} P<0.01$ versus GLP-1+Ex-9; $\boldsymbol{\Delta}_{P}<0.01$ versus all other groups. (h-j) The effect of GLP-1 receptors inhibition in the gut on glucose homeostasis during fasting-refeeding. (h) Schematic representation of experimental design. Duodenal catheter or venous and arterial catheters were implanted on day 1 . Rats were subjected to a $40 \mathrm{~h}$ fasting from 1700 hours on day 5 until 0900 hours on day 7 . Ten minutes before the completion of the 40 hour fast, rats were infused with intraduodenal saline or Ex-9 ( $n=6$ for each group). Rats were refed on regular chow at time 0 min where food intake and blood glucose were monitored for 20 min. (i) Plasma glucose levels during refeeding. (j) Cumulative food intake during refeeding. Values are shown as mean \pm S.E.M. ${ }^{\star} P<0.05$, ${ }^{* *} P<0.01$ versus saline 
intraduodenal saline-infused rats (from 104 to 120 and then to $134 \mathrm{mg} / \mathrm{dl}$; Figure 1i). However, after refeeding, blood glucose levels in rats infused with gut Ex-9 rose significantly higher than in gut saline-infused rats (from 106 to 131 and then to $150 \mathrm{mg} / \mathrm{dl}$; Figure 1i), whereas food intake was similar in both groups (Figure 1j). These results suggest that GLP-1

a

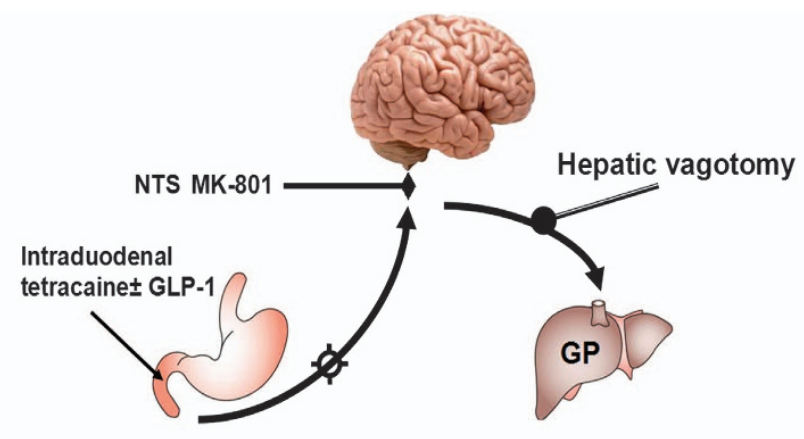

b

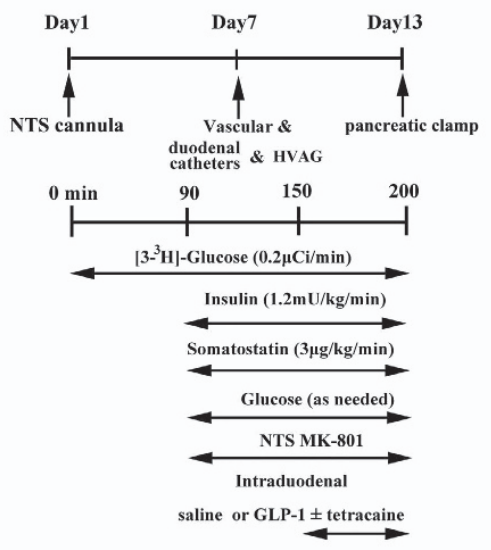

d

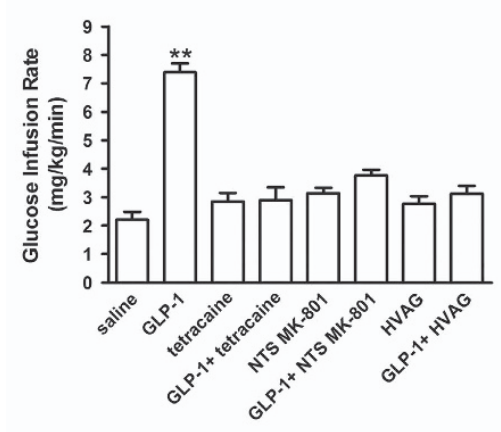

f

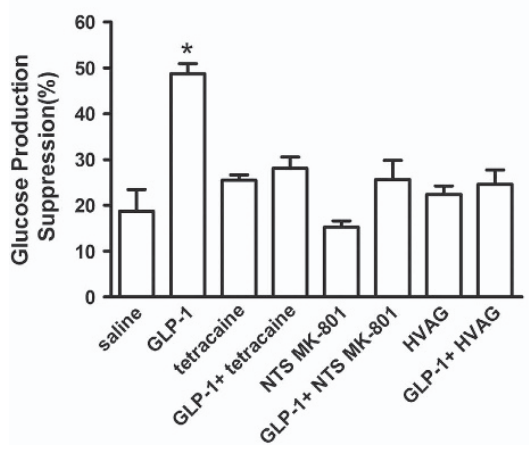

c
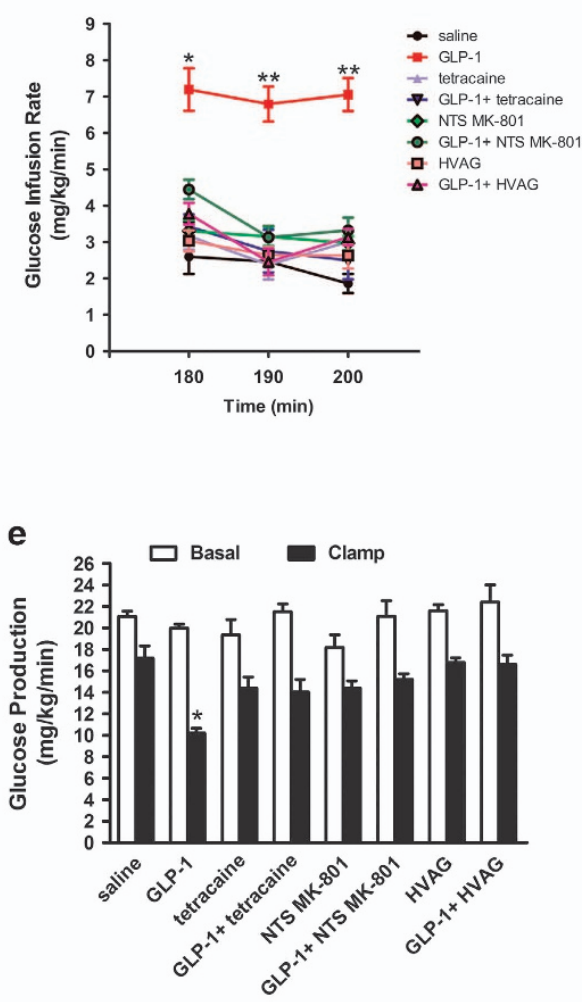

g

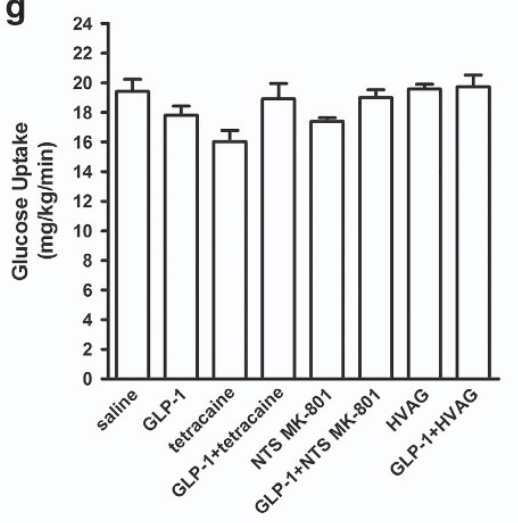


receptors can be activated by gut-nutrient sensing to regulate glucose homeostasis and is independent of changes in food intake. The physiological relevance of the ability of the duodenal GLP-1 signaling to regulate glucose production is supported by the fact that inhibition of gut GLP-1 receptors disrupts glucose homeostasis during refeeding.

Effect of duodenal GLP-1 receptor blockade on glucose turnover rates during duodenal lipid infusion. To evaluate whether activation of the gut GLP-1 receptor is required for nutrition sensing in the gut, we examined gut-lipid sensing in rats with and without inhibiting gut GLP-1 receptors (Figures 3a and b). Consistent with a previous report, ${ }^{17}$ gut-lipid infusion in rats increased GIR (Figures $3 c$ and d) and lowered HGP during the clamps (Figures $3 e$ and f). Notably, when the GLP-1 receptor inhibitor Ex-9 and lipid were co-infused into the duodenum, the roles of gut lipid to increase GIR (Figures $3 \mathrm{c}$ and $d$ ) and to lower HGP (Figures $3 e$ and f) were reversed, whereas glucose uptake was comparable in three groups (Figure $3 \mathrm{~g}$ ). These data suggest that the activation of duodenal mucosal GLP-1 receptors is necessary for the gut-lipid-sensing mechanisms to regulate HGP. In all experimental animals, body weight did not differ between groups at the time of the clamp (Supplementary Figure S4).

Duodenal GLP-1 activates PKC- $\delta$ to lower glucose production. It has been demonstrated that a selective activation of PKC- $\delta$ in the mucosal layer of the duodenum is necessary to regulate glucose metabolism. ${ }^{18}$ It has also been showed that brain GLP-1 signaling activates hypothalamic glucose-dependent $\mathrm{PKC}-\delta$ to regulate glucose metabolism and insulin sensitivity. ${ }^{19}$ To explore duodenal GLP-1dependent mechanisms, we evaluated the role of duodenal PKC- $\delta$ (Figure 4a). We first administered GLP-1 into the gut of rats and examined PKC- $\delta$ activation in the mucosal layer of the duodenum. We discovered that duodenal GLP-1 infusion significantly increased the phosphorylation of PKC- $\delta$ in the duodenal mucosa of rats (Figure 4b), suggesting a link between PKC- $\delta$ and GLP-1 signaling. To further investigate whether duodenal mucosal PKC- $\delta$ activation is required for duodenal GLP-1 signaling to regulate glucose metabolism, we inhibited duodenal mucosal $\mathrm{PKC}-\delta$ via intraduodenal co-infusion of GLP-1 with the PKC- $\delta$ inhibitor rottlerin (Figure 4a). This fully abolished the ability of GLP-1 to increase GIR (Figures 5c and d) and lower HGP (Figures 4e and $\mathrm{f}$ ), whereas gut rottlerin infusion alone had no effects (Figures $4 c-g$ ) and glucose uptake was comparable in all groups (Figure $4 \mathrm{~g}$ ).
Effect of duodenal GLP-1 on hepatic expression of PEPCK and G6Pase. Because duodenal GLP-1 significantly inhibited HGP, we examined whether expressions of PEPCK and G6Pase, two key gluconeogenic enzymes, were altered by duodenal GLP-1. Rats that received duodenal GLP-1 had significant decreased hepatic PEPCK and G6Pase mRNAs and protein expression compared with the duodenal saline control rats (Figures $5 a$ and $b$ ). These results indicate that duodenal GLP-1 strengthened the inhibitory effects of insulin on PEPCK and G6Pase in the liver and led to decreased HGP. However, co-infusion of intraduodenal tetracaine with GLP-1 fully negated the ability of GLP-1 to inhibit hepatic expression of PEPCK and G6Pase mRNAs and proteins, whereas gut tetracaine alone had no effects (Figures $5 \mathrm{a}$ and b). Similar to the effect of intraduodenal tetracaine, co-infusion of NTS MK-801 with intraduodenal GLP-1 also prevented the ability of intraduodenal GLP-1 to decrease the expression of PEPCK and G6Pase mRNAs and proteins in the liver (Figures $5 a$ and $\mathrm{c}$ ). In addition, in HVAG rats, intraduodenal GLP-1 infusions did not alter the expression of PEPCK and G6Pase mRNA and protein in the liver (Figures 5a and d). Hepatic G6Pase and PEPCK expression was comparable in gut saline with HVAG and gut saline alone groups (Figures $5 \mathrm{a}$ and $\mathrm{d}$ ). Therefore, inactivation of the hepatic branch of the vagus nerve was sufficient to disrupt hepatic autoregulation of PEPCK and G6Pase expression during intraduodenal GLP-1 infusions.

Effects of intraduodenal GLP-1 on insulin signaling in liver. To determine the mechanisms by which duodenal GLP-1 inhibited HGP, we examined hepatic phosphorylation levels of some insulin signaling molecules by western blots. As shown in Figure 5e, upon duodenal GLP-1 infusion, the phosphorylation of InsR, IRS-1, AKT and AMPK were significantly increased. When tetracaine was concomitantly infused with GLP-1 into the duodenum, the gut GLP-1 mediated increase in hepatic InsR, IRS-1, AKT and AMPK phosphorylation was completely prevented (Figure 5e). To test whether NTS NMDA receptors are required for the gut GLP-1-induced enhancement of hepatic insulin signals, we directly infused the NMDA receptor inhibitor MK-801 into the NTS. This alone did not affect hepatic insulin signals (Figure 5f). Importantly, coadministration of intraduodenal GLP-1 with NTS MK-801 prevented gut GLP-1 to enhance InsR, IRS-1, AKT and AMPK phosphorylation in the liver (Figure 5f). Furthermore, to evaluate whether NTS NMDA receptors relay the signal generated by gut GLP-1 to the liver and enhance the hepatic insulin signaling cascade, we

Figure 2 Duodenal GLP-1 inhibits glucose production by activating a gut-brain-liver neurocircuitry. (a) Schematic representation of the working hypothesis. Gut GLP-1 was co-infused with tetracaine through a duodenal catheter, which abolishes the ascending neuronal signal to the brain. A subgroup of rats was given MK-801, an NMDA receptor inhibitor, directly into the NTS. In another studies, gut GLP-1 was infused into rats that underwent HVAG. HVAG, hepatic vagotomy; GP, glucose production; NMDA, N-methyl-daspartate; NTS, nucleus of the solitary tract. (b) Experimental procedure and clamp protocol. Stereotaxic surgeries were conducted on day 1. Duodenal catheter or venous and arterial catheters were implanted on day 7. HVAG was performed immediately before the implantation of the duodenal and vascular catheters. (c-e) Gut GLP-1 infusion increased glucose infusion rate and lowered GP. Rats that received tetracaine in the gut, MK-801 in the NTS or HVAG failed to respond to duodenal GLP-1 to increase the glucose infusion rate and lower GP. (f) Suppression of GP during the clamp expressed as the percentage decrease from basal GP. (g) Glucose uptake was unchanged in all groups. Values are shown as mean \pm S.E.M. (saline $(n=6)$, GLP-1 $(n=6)$, Tetracaine $(n=5)$, GLP-1+tetracaine $(n=7)$, NTS MK-801 $(n=5)$, GLP- $1+$ NTS MK- $801(n=8)$, HVAG $(n=6)$, GLP-1 + HVAG $(n=8)) .{ }^{*} P<0.05,{ }^{* *} P<0.01$, versus all other groups 
a
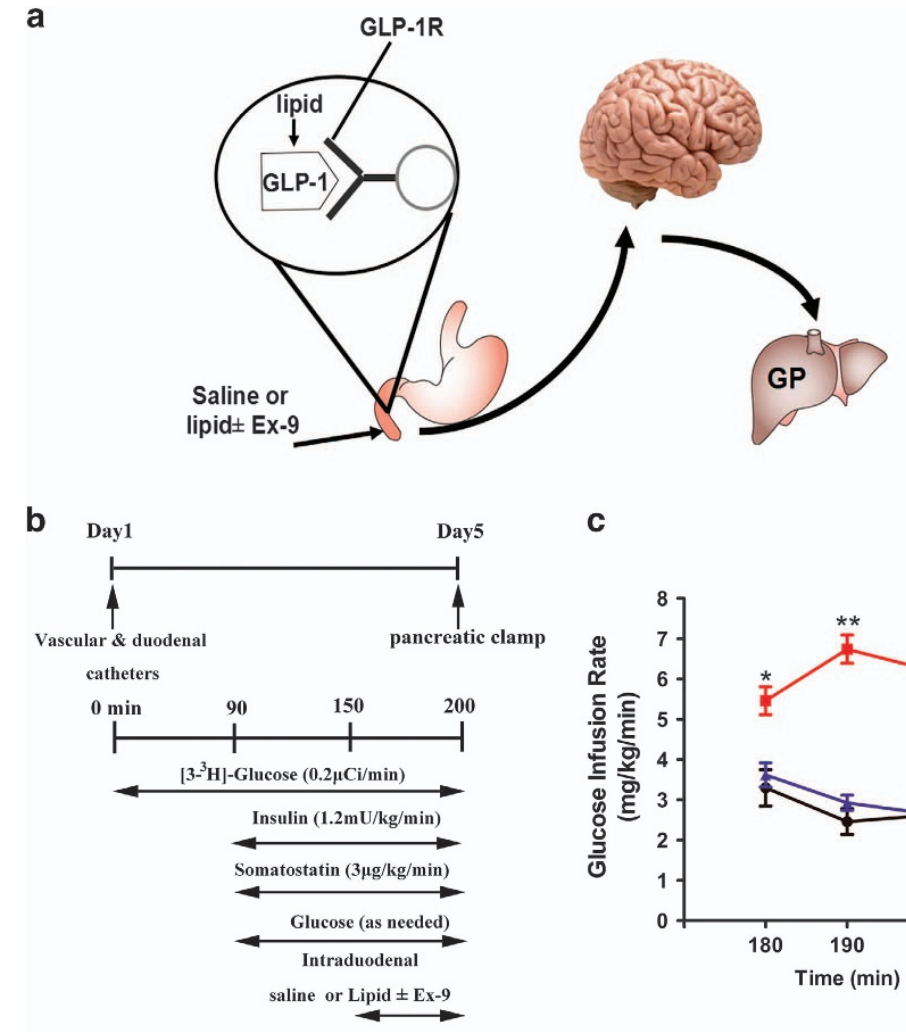

c

d
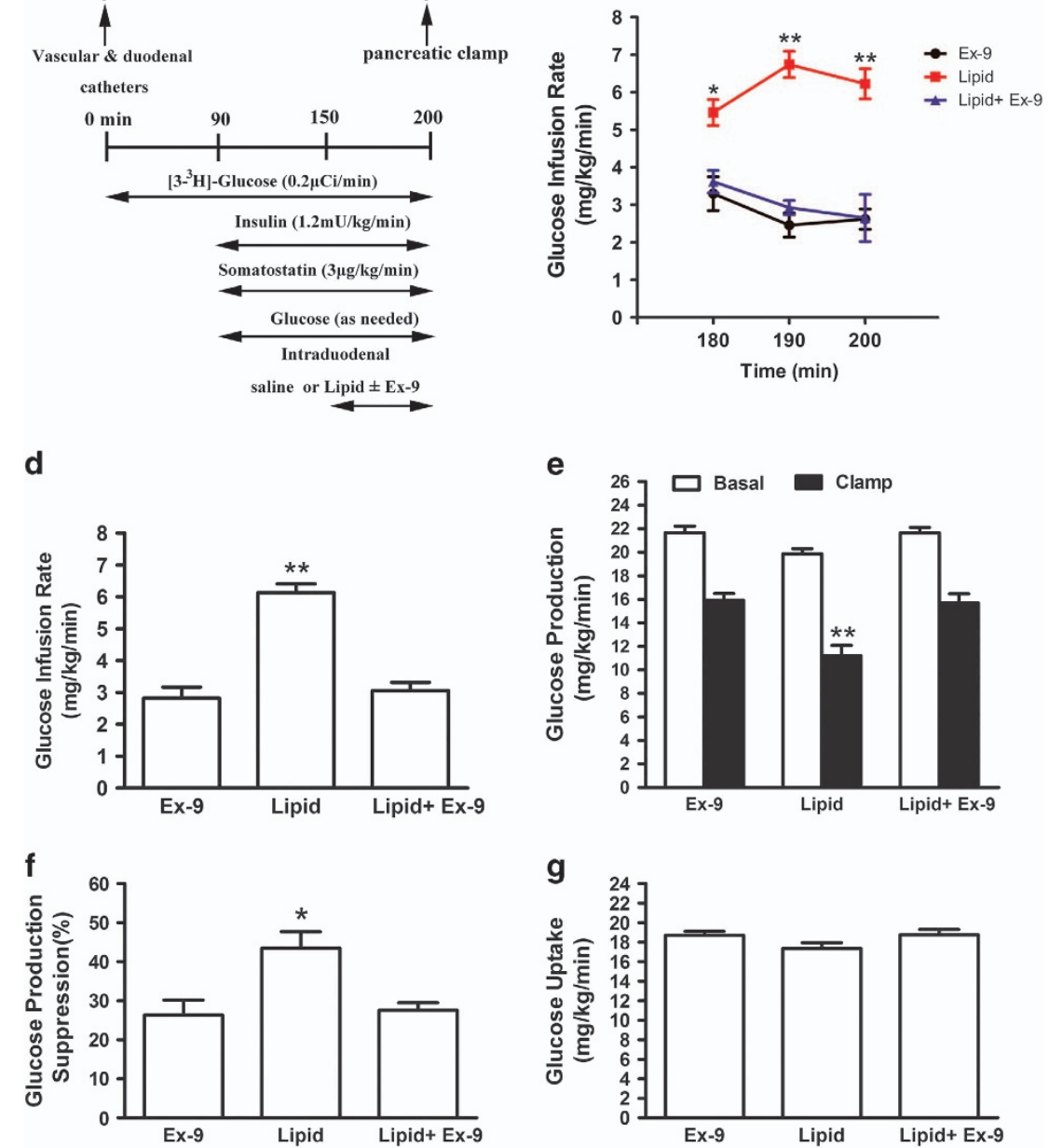

Figure 3 GLP-1 receptor is required for duodenal lipids to suppress hepatic glucose production. (a) Schematic representation of the working hypothesis. Lipid with Ex-9 or saline was infused through a duodenal catheter. (b) Experimental procedure and clamp protocol. (c-f) Gut lipids infusion increased the GIR (c and d), and decreased GP (e and $\mathbf{f})$. When duodenal lipid was co-infused with Ex-9, the effects of lipids on GIR and GP were abolished. (g) Glucose uptake was unchanged in all groups. Values are shown as mean \pm S.E.M. $(\operatorname{Ex}-9(n=5)$, lipid $(n=8)$, lipid+Ex-9 $(n=8)) .{ }^{*} P<0.05,{ }^{* \star} P<0.01$ versus all other groups

Figure 4 Gut GLP-1 inhibits hepatic glucose production through PKC- $\delta$ activation. (a) Schematic of working hypothesis (left), experimental procedure and clamp protocol (right). GLP-1 was infused with or without rottlerin, a PKC- $\delta$ specific inhibitor, through a duodenal catheter. GLP-1R, GLP-1 receptor; GP, glucose production; ROT, rottlerin. (b) Representative western blots $(n=6)$ of PKC- $\delta$ in the mucosal layer of the duodenum. (c-f) Gut GLP-1 infusion increased the GIR (c and d), and decreased GP (e and f). When duodenal GLP-1 was co-infused with rottlerin, the effects of GLP-1 on GIR and GP were abolished. (g) Glucose uptake was comparable in all groups. Values are shown as mean \pm S.E.M. (saline $(n=6)$, GLP-1 $(n=6)$, saline+ROT $(n=5)$, GLP-1+ROT $(n=5))$. ${ }^{*} P<0.05,{ }^{* \star} P<0.01$ versus all other groups 
repeated duodenal GLP-1 infusion experiments in rats that underwent the hepatic vagal branch vagotomy. When duodenal GLP-1 infusion was co-administered with HVAG, the ability of gut GLP-1 to enhance hepatic InsR, IRS-1, AKT and AMPK phosphorylation was abolished, whereas HVAG alone did not affect hepatic insulin signals (Figure $5 \mathrm{~g}$ ). a
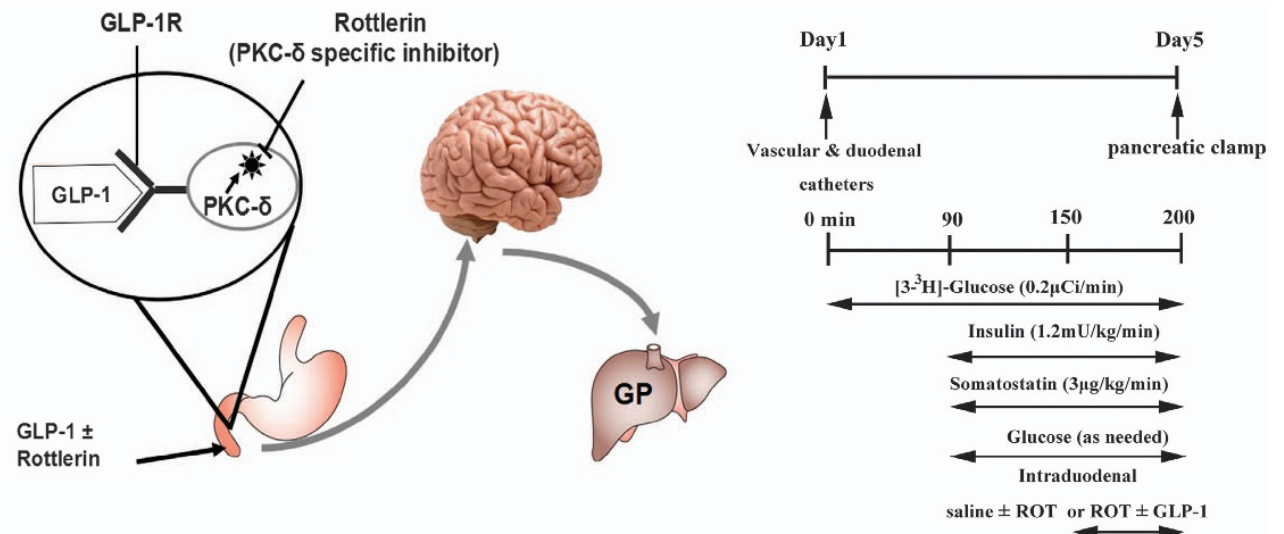

b

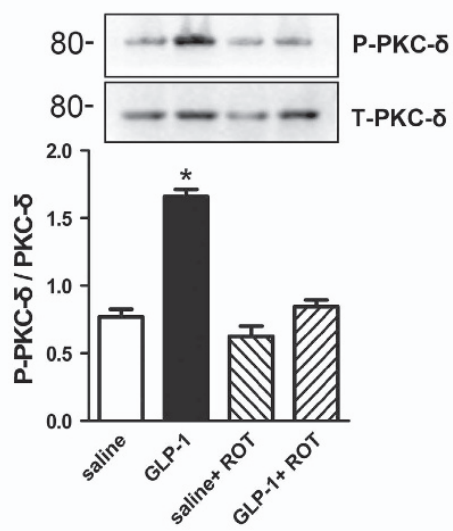

d

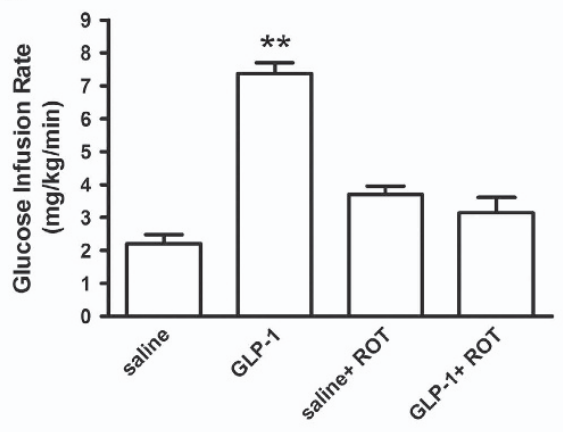

f

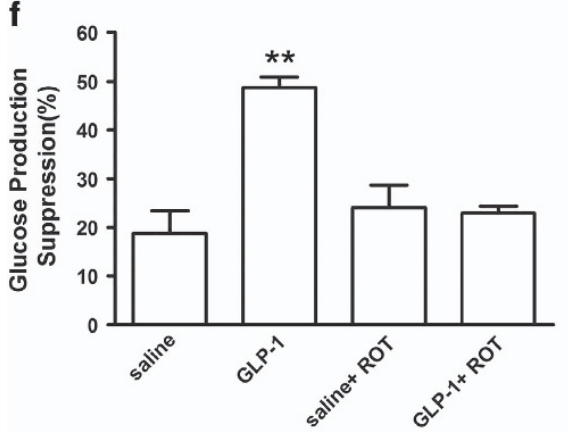

C
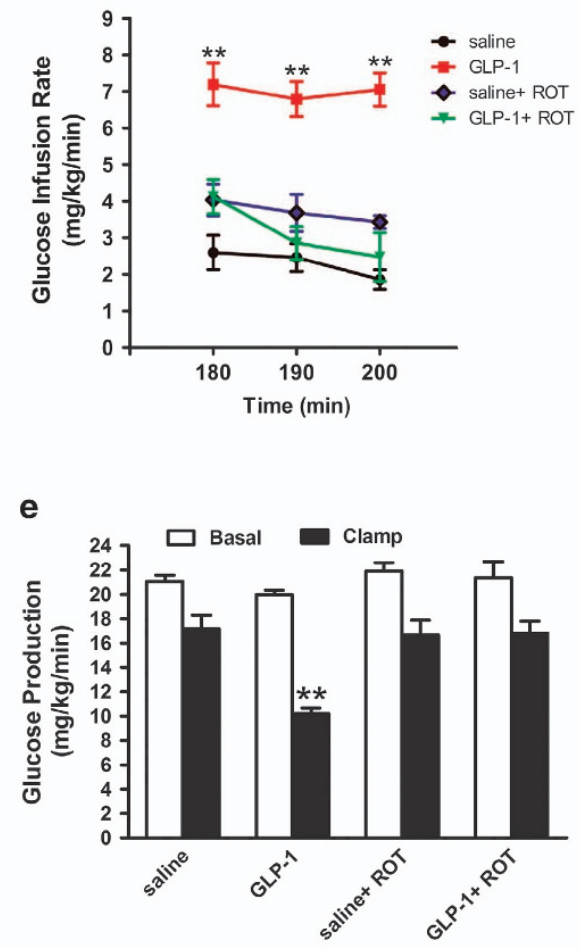

g

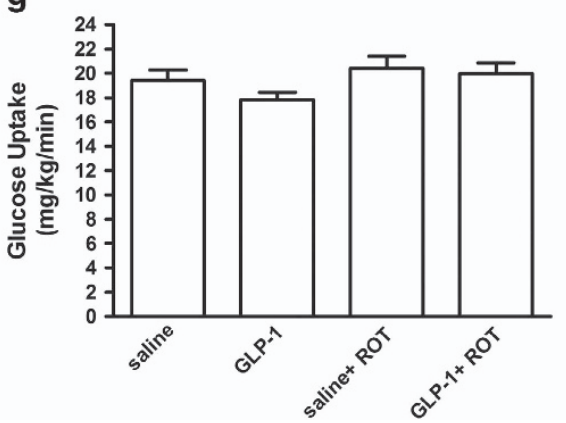



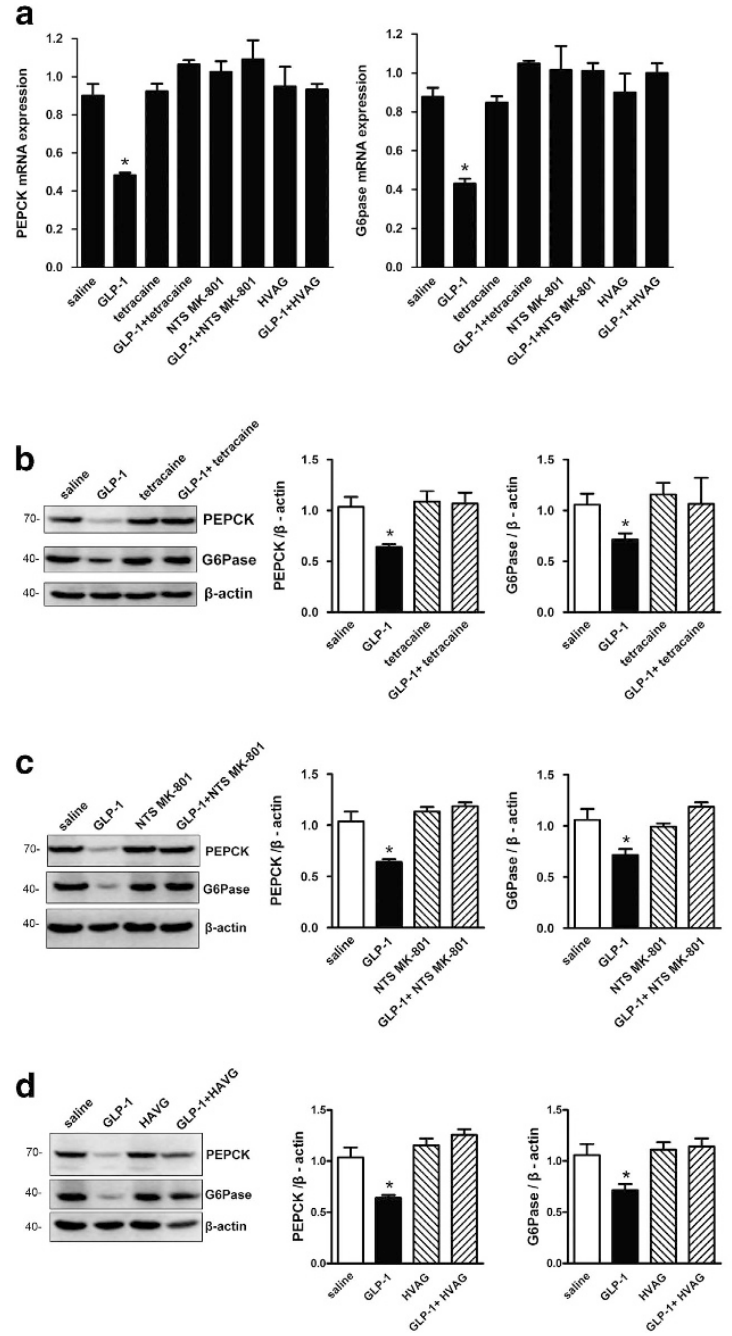
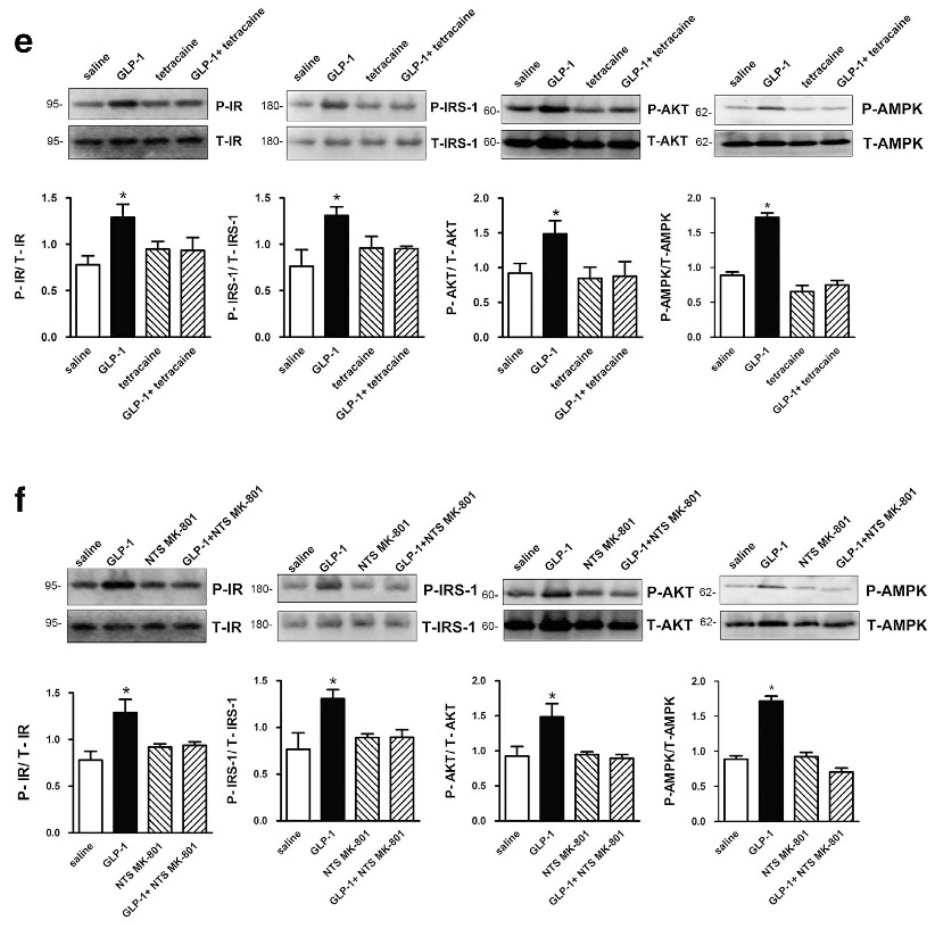

g
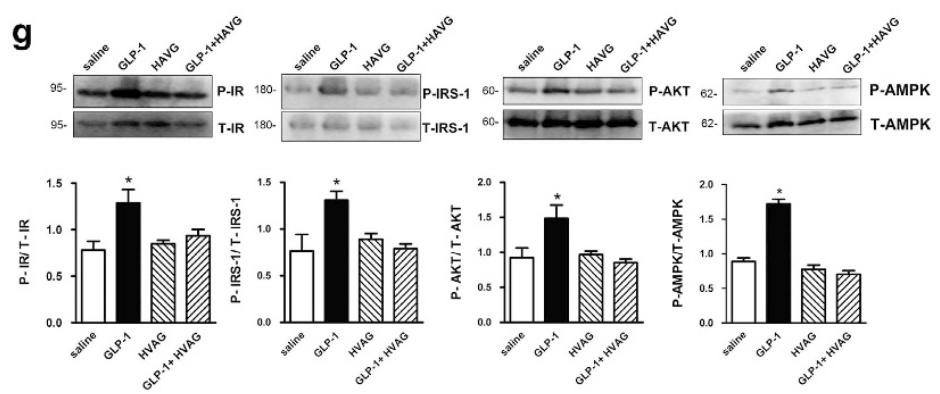

Figure 5 Duodenal GLP-1 suppresses hepatic PEPCK and G6Pase expression through a gut-brain-liver neurocircuitry. Intraduodenal GLP-1 infusion in rats suppressed hepatic PEPCK and G6Pase mRNA $(n=6)(\mathbf{a})$ and protein expression $(n=6)(\mathbf{b}-\mathbf{d})$. In contrast, rats that received tetracaine (b), MK-801 in the NTS (c) or HVAG (d) failed to respond to duodenal GLP-1 to suppress hepatic PEPCK and G6Pase expression. HVAG, hepatic vagotomy; NTS, nucleus of the solitary tract. Values are shown as mean \pm S.E.M. (saline $(n=6)$, GLP-1 $(n=6)$, Tetracaine $(n=5)$, GLP-1+tetracaine $(n=8)$, NTS MK-801 $(n=5)$, GLP-1+NTS MK- $801(n=7)$, HVAG $(n=5)$, GLP-1+HVAG $(n=7))$. ${ }^{*} P<0.01$ versus all other groups. (e-g) Duodenal GLP-1 augments hepatic insulin signaling through a gut-brain-liver neurocircuitry. Representative western blots $(n=6)$ and ratios of protein levels of phosphorylated InsR, IRS-1, AKT and AMPK to total InsR, IRS-1, AKT and AMPK in livers from experiments shown in Figure 2b. HVAG, hepatic vagotomy; NTS, nucleus of the solitary tract. Values are shown as mean \pm S.E.M. (saline $(n=6)$, GLP-1 $(n=6)$, Tetracaine $(n=5)$, GLP-1+tetracaine $(n=5)$, NTS MK-801 $(n=5)$, GLP-1+NTS MK-801 $(n=5)$, HVAG $(n=5)$, GLP-1+HVAG $(n=5)) .{ }^{*} P<0.01$ versus all other groups

Collectively these data indicate that the NTS relays a signal generated by intestinal GLP-1 to the liver to enhance hepatic insulin signaling. Finally, to investigate the effects of gut GLP-1 on insulin signaling molecules in other insulin target issues, we assessed the phosphorylation levels of InsR and Akt in adipose and muscle tissues during duodenal GLP-1 infusion. We found that neither gut GLP-1 nor any other administration affected the phosphorylation of insulin signaling molecules in both adipose and muscle tissues (Supplementary Figures S5A and B).

\section{Discussion}

Diabetes and obesity are characterized by excessive rates of HGP. $^{20}$ Therefore, it appears important to assess whether different gut-peptide hormones, such as CCK, peptide YY and GLP-1(via intraduodenal infusion or oral ingestion) regulate glucose production.

In recent years, a series of papers published by the Lam laboratory ${ }^{17,18,21,22}$ has highlighted the existence of a gutbrain-liver axis in the regulation of glucose homeostasis through combination with duodenal tetracaine infusion (inhibiting gut vagal afferent fibers), ${ }^{23}$ MK-801 infusion (the NMDA receptor inhibitor) ${ }^{24}$ and hepatic branch vagotomy. ${ }^{25}$ Using this neural network, Lam and co-workers ${ }^{17,18}$ and other groups ${ }^{26}$ investigated the effects of intestinal nutrients and hormones on HGP and fat metabolism. Along this line of evidence, it is important to continue dissecting the physiological role of some novel signaling molecules within the duodenum in regulating glucose homeostasis via this gut-brain-liver axis. Therefore, 
the main objective of this study was to evaluate for the first time the role of the gut GLP-1 to regulate HGP and hepatic insulin signal. In this article, we have specifically shown the following: (1) the gut GLP-1 participates the regulation of HGP and hepatic insulin signaling in rodents; (2) gut GLP-1 requires activation of GLP-1R in the intestinal mucosal layer; (3) activation of $\mathrm{PKC}-\delta$ in the gut mucosal layer is required for gut GLP-1 to lower HGP, suggesting that PKC- $\delta$ activation lies downstream of GLP-1 signaling; (4) a neuronal network activation is required for gut GLP-1 to lower glucose production in normal rats. These data highlight a previously unappreciated role of duodenal GLP-1 signaling in the neural regulation of glucose homeostasis.

In previous studies, the main hormonal effect of GLP-1 was considered to be stimulation of glucose-induced insulin secretion. ${ }^{27}$ In this study, we postulate that GLP-1 released from the duodenal mucosa acts at local GLP-1 receptors in vagal afferent nerve that innervate the lamina propria of the mucosa. Therefore, to examine whether intestinal GLP-1 regulates glucose production, we activated duodenal GLP-1 signaling via direct intraduodenal GLP-1 administration. We found that an increase of GLP-1 in the duodenum lowers glucose production, inhibits the hepatic expression of G6Pase and PEPCK (two key gluconeogenic enzymes) and enhances hepatic insulin signaling. These changes were independent of changes in circulating GLP-1 or insulin levels. These findings suggested that the increase of gut GLP-1 triggers a gut hormone sensor to inhibit HGP and favor hepatic glycogen deposition. Furthermore, because co-infusion of the GLP-1 receptor inhibitor Ex-9 with GLP-1 into the duodenum abolished the ability of GLP-1 to inhibit HGP, duodenal GLP-1 receptors appear to be required for this potent control of gut GLP-1 on HGP.

Given that intestinal nutrients, such as lipids or glucose, stimulate local release of gut-peptide hormones. We investigated whether GLP-1 receptors in the gut are required for the gut-nutrient regulation on HGP with fasting-refeeding studies and intraduodenal coadministration of intralipid with Ex-9. We found that gut Ex-9 administration disrupted glucose homeostasis during refeeding and reversed the ability of gut lipids to increase GIR and lower HGP during the pancreaticeuglycemic clamps (PECs). These data strengthen the role of intestinal GLP-1 on glucose production and further indicate that GLP-1 receptors are required for gut-nutrient sensing. Noteworthy, the previous studies from Cheung et al. ${ }^{17}$ demonstrated that CCK-A receptors are also required for gut-nutrient sensing. It is also of interest that Beglinger et al. ${ }^{27}$ found that blockade of CCK-1 receptors by a specific antagonist (DEXLOX) markedly reduced duodenal lipid stimulated GLP-1 release. They and others ${ }^{28}$ proposed that the specific products of fat digestion, including long-chain fatty acids, stimulate the release of CCK; CCK in turn acts on CCK-1 receptors, which then initiate a series of digestive actions including modulation of GLP-1 release (a fat-CCKGLP-1 axis). Therefore, it is likely that both CCK and GLP-1 are required for gut-nutrient sensing to lower glucose production.

Recently, it has been reported that PKC- $\delta$ is expressed in the duodenum may be involved in the regulation of glucose production. ${ }^{29}$ In this study, we demonstrate that activation of the duodenal PKC- $\delta$ is necessary for duodenal GLP-1 to regulate glucose metabolism, thereby revealing a duodenal GLP-1 and PKC- $\delta$ signaling axis that lowers HGP in the presence of basal insulin levels. This finding also suggests that activation of duodenal PKC- $\delta$ may lie downstream of GLP-1 signaling. However, an important unanswered question remains as to how duodenal GLP-1- triggers a neuronal network leading to the inhibition of glucose production. We propose that gut GLP-1-PKC- $\delta$ signaling first elicits an afferent neuronal signal to the hindbrain. The hindbrain then relays this signal to the liver to lower HGP. Here we used three independent yet complementary approaches to investigate whether a neuronal network involving the gut, brain and liver mediates the suppressive effects of duodenal GLP-1 on HGP.

We first infused the topical anesthetic tetracaine to inhibit the neurotransmission of vagal afferent fibers innervating the upper intestine in the absence or presence of gut GLP-1. Tetracaine administration significantly reduced the ability of duodenal GLP-1 to enhance hepatic insulin signaling, to inhibit gluconeogenic enzymes and to lower HGP, confirming that gut GLP-1 triggers a neuronal signal in the intestine to lower HGP.

The vagal afferent nerves terminate at the nucleus of the NTS within the DVC. Glutamatergic neurotransmission has been demonstrated in gut-recipient NTS neurons, and NMDA receptors have been localized to vagal afferent terminals in the hindbrain NTS. ${ }^{30,31}$ NMDA receptors in the gut-recipient neurons in NTS of the hindbrain mediate gut signals initiated by hormones or nutrients to regulate food intake and glucose homeostasis. ${ }^{2,3}$ We inhibited NMDA receptor-mediated neuronal transmission in the DVC via direct NTS-targeted administration of the NMDA receptor blocker MK-801. As expected, NTS MK-801 fully reversed the ability of gut GLP-1 to enhance hepatic insulin signaling and lower glucose production. These results support the idea that NTS transmission relays afferent neuronal signals triggered by gut GLP-1 to lower HGP and enhance hepatic insulin signaling.

The parasympathetic vagus nerve appears to be a crucial link in the CNS control of hepatic metabolism. ${ }^{32}$ It has been reported that leptin ${ }^{33}$ and GLP- $1^{34}$ directly control liver and/or WAT metabolism, and most of those signals require an intact sympathetic nervous system. To evaluate whether the hindbrain relays signals induced by gut GLP-1 to the liver to lower HGP, we repeated the gut GLP-1 infusion protocol in rats that underwent vagotomy of the hepatic branch to block the neurocommunication between the brain and liver. As expected, hepatic vagotomy inhibited the ability of gut GLP-1 to increase GIR, lower HGP and enhance hepatic insulin signaling. These results strengthen our hypothesis that the upper-gut-GLP-1 induced neuronal signals are first processed by the NTS and are then relayed to the liver. Collectively, it appears plausible that upper intestine nutrients, such as lipids, stimulate the release of GLP-1 from mucosal cells which then bind to GLP-1 receptors on vagal afferents nerves in the duodenum and activate mucosal PKC- $\delta$. By activating vagus afferent nerves, hormone or nutrient derived signals arrive at the NTS and activate the neurons in the hindbrain region and NMDA receptors. Finally, these signals are relayed from the NTS to the liver via the efferent branch of the hepatic vagal nerve to lower HGP (Supplementary Figure S6). 
In conclusion, our data show that a rise in intestinal GLP-1 activates GLP-1 receptors and stimulates duodenal mucosal PKC- $\delta$ activation triggering a gut-brain-liver neuronal axis which lowers glucose production in normal rodents.

\section{Materials and Methods \\ Animal preparation, stereotaxic surgery, duodenal and intrave- nous cannulations, and selective hepatic branch vagotomy.} These sections are described in detail in Supplementary Information.

Intraduodenal infusions and treatments. To examine the dosedependent effects of intraduodenal GLP-1 on the GIR during PECs, different concentrations of liraglutide (Novo Nordisk, Copenhagen, Denmark) or Exenatide (AstraZeneca, Cambridge, UK) $(0,10,30,60 \mathrm{pmol} / \mathrm{l})$ were continuously infused to the duodenum through the duodenal catheter during the 150-200 min of clamp (Supplementary Figure S2). For all experiments, we infused GLP-1 (Exenatide) into the duodenum at $30 \mathrm{pmol} / \mathrm{kg} / \mathrm{min}$, which was shown to suppress HGP (Figure 1). In addition, the following materials were also infused into the duodenum at a rate of $0.6 \mathrm{ml} / \mathrm{h}$ during the pancreatic clamp when required: (1) saline; (2) GLP-1 receptor antagonist Exendin Fragment 9-39 (Ex-9) (Aladdin, Shanghai, China; 300 pmol/kg/ $\mathrm{min}$ ); ${ }^{35}$ (3) tetracaine (Sigma-Aldrich, Shanghai, China; $0.01 \mathrm{mg} / \mathrm{min}$ ); (4) $20 \%$ intralipids (Sino-Swed Pharmaceutical Corp. Ltd, Beijing, China; $0.03 \mathrm{kcal} / \mathrm{min}$ ) and (5) rottlerin: a PKC- $\delta$ inhibitor (Sigma-Aldrich; $60 \mu \mathrm{mol} / /)^{29}$

PEC procedure. Rats were limited to $20 \mathrm{~g}$ food to ensure the same nutritional post-absorptive status at the night before the PECs. A continuous infusion of highperformance liquid chromatography-purified $\left[3-\mathrm{H}^{3}\right]$ glucose (PerkinElmer, Waltham, MA, USA; $6 \mu \mathrm{Ci}$ bolus, $0.2 \mu \mathrm{Ci} / \mathrm{min})$ was initiated at $0 \mathrm{~min}$ and maintained throughout the experiment to assess glucose metabolism. The PECs was started $90 \mathrm{~min}$ after the tracer infusion to allow the tracer to reach steady state. Insulin $(1.2 \mathrm{mU} / \mathrm{kg} / \mathrm{min})$ and somatostatin $(3 \mu \mathrm{g} / \mathrm{kg} / \mathrm{min})$ were continuously infused, and a variable infusion of $25 \%$ glucose was started and adjusted every $10 \mathrm{~min}$ to maintain blood glucose at $\sim 7 \mathrm{mmol}$ (Figure 1b). Blood glucose was monitored with a portable glucometer and various study solutions were infused through the right internal jugular vein catheter. Intraduodenal infusions were initiated from $t=150$ to $200 \mathrm{~min}$ to determine the effects of different gut treatments on glucose production. In a subgroup of rats undergoing NTS treatment procedures, MK-801, an NMDA receptor inhibitor (Sigma-Aldrich, $0.03 \mathrm{ng} / \mathrm{min}$ ), was initiated at $t=90$ to $200 \mathrm{~min}$ until the end of the clamp. The $100 \mu \mathrm{l}$ of blood samples were obtained from the left carotid artery catheter at $0,60,90,180,190$ and $200 \mathrm{~min}$ for determination of insulin, GLP-1, FFA, triglyceride, total cholesterol and glucose-specific activity. Each blood sample was replaced by the same volume of fresh whole blood from a donor rat. At the end of the clamp, the rats were anesthetized, portal vein blood was obtained and tissue samples were freeze-clamped in situ with aluminum tongs precooled in liquid nitrogen and stored at $-80^{\circ} \mathrm{C}$ for further analysis.

Fasting-feeding study. After the vascular and duodenal surgery, rats were allowed 5 days to recovery. A subgroup of rats was fasted beginning at $5 \mathrm{PM}$ the day before the onset of the experiment. Rats were refed after fasting for $40 \mathrm{~h}$. Rats were subjected to a continuous intraduodenal infusion of either saline or Ex-9 $(300 \mathrm{pmol} /$ $\mathrm{kg} / \mathrm{min}$ ) for $30 \mathrm{~min}$ (Figure 1h). Blood glucose levels were measured at $t=0,10$ and $20 \mathrm{~min}$. Cumulative food intake was measured at the end of this protocol.

Immunohistochemistry, RNA extraction and quantitative realtime RT-PCR, western blot analyses and analytical procedure. These sections are described in detail in Supplementary Information.

Statistical analyses. All groups from our data showed normal variance, and thus we analyzed results using an unpaired Student's $t$-test for the analyses of two groups or ANOVA followed by Tukey's post hoc test when comparisons were made for more than two groups. All results are presented as means \pm S.E.M. $P<0.05$ was considered significant. Data between $t=60-90 \mathrm{~min}$ and $t=180-200 \mathrm{~min}$ were averaged for the basal and clamp conditions, respectively. No blinding was done for any of the experimental procedures.

\section{Conflict of Interest}

The authors declare no conflict of interest.
Acknowledgements. This work was supported by research grants from National Natural Science Foundation of China (81270913, 81470045 and 81570752) and grant from the AstraZeneca.

\section{Author contributions}

MY, LY and JW performed experiments, analyzed data and participated in text. SW and $\mathrm{JY}$ designed and established the model system. $\mathrm{JX}$ and $\mathrm{YJ}$ performed experiments and analyzed data. YL contributed to western blots. AZZ, CL, XZ and GB participated in manuscript writing and revision. GY conceived the project, supervised the overall project and wrote the manuscript. LL and GYare the persons who take full responsibility for the work as a whole, including (if applicable) the study design, access to data, and the decision to submit and publish the manuscript.

1. Coll AP, Farooqi IS, O'Rahilly S. The hormonal control of food intake. Cell 2007; 129: 251-262.

2. Cummings DE, Overduin J. Gastrointestinal regulation of food intake. J Clin Invest 2007; 117: $13-23$.

3. Murphy KG, Bloom SR. Gut hormones and the regulation of energy homeostasis. Nature 2006; 444: 854-859.

4. Eissele R, Goke R, Willemer S, Harthus HP, Vermeer H, Arnold R et al. Glucagon-like peptide- 1 cells in the gastrointestinal tract and pancreas of rat, pig and man. Eur J Clin Invest 1992; 22: 283-291.

5. Baggio LL, Drucker DJ. Biology of incretins: GLP-1 and GIP. Gastroenterology 2007; 132: 2131-2157.

6. Ruttimann EB, Arnold M, Hillebrand JJ, Geary N, Langhans W. Intrameal hepatic portal and intraperitoneal infusions of glucagon-like peptide-1 reduce spontaneous meal size in the rat via different mechanisms. Endocrinology 2009; 150: 1174-1181.

7. Young AA, Gedulin BR, Bhavsar S, Bodkin N, Jodka C, Hansen B et al. Glucose-lowering and insulin-sensitizing actions of exendin-4: studies in obese diabetic (ob/ob, db/db) mice, diabetic fatty Zucker rats, and diabetic rhesus monkeys (Macaca mulatta). Diabetes 1999; 48: 1026-1034.

8. Li L, Yang G, Li Q, Tan X, Liu H, Tang Y et al. Exenatide prevents fat-induced insulin resistance and raises adiponectin expression and plasma levels. Diabetes Obes Metab 2008; 10: 921-930.

9. Zander M, Madsbad S, Madsen JL, Holst JJ. Effect of 6-week course of glucagon-like peptide 1 on glycaemic control, insulin sensitivity, and beta-cell function in type 2 diabetes: a parallel-group study. Lancet 2002; 359: 824-830.

10. Imeryuz N, Yegen BC, Bozkurt A, Coskun T, Villanueva-Penacarrillo ML, Ulusoy NB. Glucagon-like peptide-1 inhibits gastric emptying via vagal afferent-mediated central mechanisms. Am J Physiol 1997; 273(Pt 1): G920-G927.

11. Wang $Y$, Li L, Yang M, Liu H, Boden G, Yang G. Glucagon-like peptide-1 receptor agonists versus insulin in inadequately controlled patients with type 2 diabetes mellitus: a metaanalysis of clinical trials. Diabetes Obes Metab 2011; 13: 972-981.

12. Sjoholm A. Impact of glucagon-like peptide-1 on endothelial function. Diabetes Obes Metab 2009; 11(Suppl 3): 19-25.

13. Kedees MH, Guz Y, Grigoryan M, Teitelman G. Functional activity of murine intestinal mucosal cells is regulated by the glucagon-like peptide-1 receptor. Peptides 2013; 48: 36-44.

14. Pyke C, Heller RS, Kirk RK, Orskov C, Reedtz-Runge S, Kaastrup P et al. GLP-1 receptor localization in monkey and human tissue: novel distribution revealed with extensively validated monoclonal antibody. Endocrinology 2014; 155: 1280-1290.

15. Holst JJ. The physiology of glucagon-like peptide 1. Physiol Rev 2007; 87: 1409-1439.

16. Duran-Sandoval D, Cariou B, Percevault F, Hennuyer N, Grefhorst A, van Dijk TH et al. The farnesoid $\mathrm{X}$ receptor modulates hepatic carbohydrate metabolism during the fastingrefeeding transition. J Biol Chem 2005; 280: 29971-29979.

17. Cheung GW, Kokorovic A, Lam CK, Chari M, Lam TK. Intestinal cholecystokinin controls glucose production through a neuronal network. Cell Metab 2009; 10: 99-109.

18. Wang PY, Caspi L, Lam CK, Chari M, Li X, Light PE et al. Upper intestinal lipids trigger a gutbrain-liver axis to regulate glucose production. Nature 2008; 452: 1012-1016.

19. Cabou C, Vachoux C, Campistron G, Drucker DJ, Burcelin R. Brain GLP-1 signaling regulates femoral artery blood flow and insulin sensitivity through hypothalamic PKC-delta. Diabetes 2011; 60: 2245-2256.

20. Jeng CY, Sheu WH, Fuh MM, Chen YD, Reaven GM. Relationship between hepatic glucose production and fasting plasma glucose concentration in patients with NIDDM. Diabetes 1994; 43: $1440-1444$.

21. Cote CD, Rasmussen BA, Duca FA, Zadeh-Tahmasebi M, Baur JA, Daljeet M et al. Resveratrol activates duodenal Sirt1 to reverse insulin resistance in rats through a neuronal network. Nat Med 2015; 21: 498-505.

22. Duca FA, Cote CD, Rasmussen BA, Zadeh-Tahmasebi M, Rutter GA, Filippi BM et al. Metformin activates a duodenal Ampk-dependent pathway to lower hepatic glucose production in rats. Nat Med 2015; 21: 506-511.

23. Greenberg D, Smith GP, Gibbs J. Intraduodenal infusions of fats elicit satiety in sham-feeding rats. Am J Physiol 1990; 259(Pt 2): R110-R118.

24. Treece BR, Covasa M, Ritter RC, Burns GA. Delay in meal termination follows blockade of $\mathrm{N}$-methyl-D-aspartate receptors in the dorsal hindbrain. Brain Res 1998; 810: 34-40. 
25. Matsuhisa M, Yamasaki Y, Shiba Y, Nakahara I, Kuroda A, Tomita T et al. Important role of the hepatic vagus nerve in glucose uptake and production by the liver. Metabolism 2000; 49: $11-16$.

26. Blouet C, Schwartz GJ. Duodenal lipid sensing activates vagal afferents to regulate nonshivering brown fat thermogenesis in rats. PLOS ONE 2012; 7: e51898.

27. Beglinger S, Drewe J, Schirra J, Goke B, D'Amato M, Beglinger C. Role of fat hydrolysis in regulating glucagon-like Peptide-1 secretion. J Clin Endocrinol Metab 2010; 95: 879-886.

28. Gaylinn BD, Thorner MO. Luminal influences to orchestrate gastroenterological hormone secretion: the fat, long-chain Fatty Acid, cholecystokinin, glucagon-like Peptide 1 axis. J Clin Endocrinol Metab 2010; 95: 503-504.

29. Kokorovic A, Cheung GW, Breen DM, Chari M, Lam CK, Lam TK. Duodenal mucosal protein kinase C-delta regulates glucose production in rats. Gastroenterology 2011; 141: 1720-1727.

30. Aicher SA, Sharma S, Pickel VM. N-methyl-D-aspartate receptors are present in vagal afferents and their dendritic targets in the nucleus tractus solitarius. Neuroscience 1999; 91: 119-132.

31. Berthoud HR, Earle T, Zheng H, Patterson LM, Phifer C. Food-related gastrointestinal signals activate caudal brainstem neurons expressing both NMDA and AMPA receptors. Brain Res 2001; 915: 143-154.

32. Lam TK, Schwartz GJ, Rossetti L. Hypothalamic sensing of fatty acids. Nat Neurosci 2005 8: $579-584$.

33. Buettner C, Muse ED, Cheng A, Chen L, Scherer T, Pocai A et al. Leptin controls adipose tissue lipogenesis via central, STAT3-independent mechanisms. Nat Med 2008; 14 $667-675$.
34. Nogueiras R, Perez-Tilve D, Veyrat-Durebex C, Morgan DA, Varela L, Haynes WG et al. Direct control of peripheral lipid deposition by CNS GLP-1 receptor signaling is mediated by the sympathetic nervous system and blunted in diet-induced obesity. J Neurosci 2009; 29: $5916-5925$.

35. Wang Z, Wang RM, Owji AA, Smith DM, Ghatei MA, Bloom SR. Glucagon-like peptide-1 is a physiological incretin in rat. J Clin Invest 1995; 95: 417-421.

Cell Death and Disease is an open-access journal published by Nature Publishing Group. This work is

licensed under a Creative Commons Attribution 4.0 International License. The images or other third party material in this article are included in the article's Creative Commons license, unless indicated otherwise in the credit line; if the material is not included under the Creative Commons license, users will need to obtain permission from the license holder to reproduce the material. To view a copy of this license, visit http://creativecommons.org/licenses/by/4.0/

(C) The Author(s) 2017

Supplementary Information accompanies this paper on Cell Death and Disease website (http://www.nature.com/cddis) 